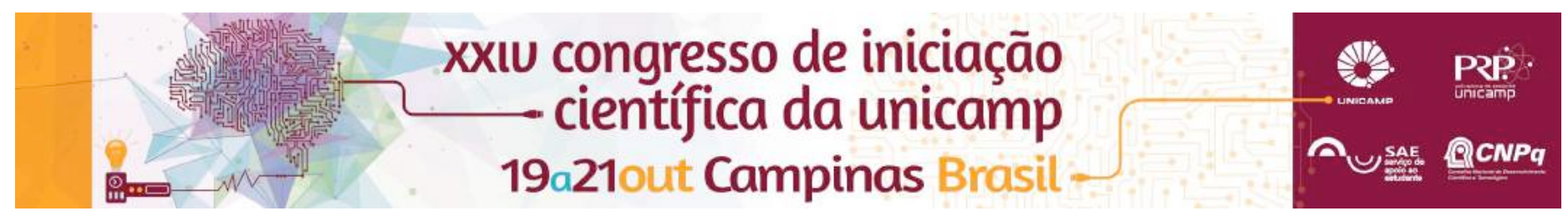

\title{
Avaliação da presença de processo inflamatório na doença periodontal induzida por contato prematuro unilateral posterior em ratos
}

\author{
Willian S Zanelli*, Henrique Abdalla, Ricardo Bonfante, Nádia C Fávaro-Moreira, Cristina M Maganin, Frederico \\ Andrade e Silva, Juliana T Clemente Napimoga
}

\section{Resumo}

Tem sido demonstrado que o trauma oclusal participa da etiologia da doença periodontal através de uma combinação de fatores resultando em dor que, provavelmente, está relacionada ao estabelecimento de reação inflamatória. O objetivo deste estudo foi, portanto, avaliar a presença da resposta inflamatória local no periodonto de elemento dental reabilitado com coroas metálicas que simulam o trauma oclusal. A avaliação da resposta inflamatória foi realizada através da quantificação de mediadores como TNF- $\alpha$ e IL-1 $\beta$ no tecido periodontal de ratos machos Wistar $( \pm 150 \mathrm{~g}, \mathrm{n}=$ 4-6/grupo, protocolo aprovado pela Comissão de Ética no Uso de Animais \#4001-1 da FOP/UNICAMP). Os animais foram anestesiados por via intramuscular e posicionados em um dispositivo para possibilitar a abertura bucal para a cimentação (cimento resinoso) de coroas metálicas fundidas de 0,4 $\mathrm{mm}$ ou $0,7 \mathrm{~mm}$ de espessura, recobrindo todas as faces do primeiro molar inferior esquerdo com exceção da face distal, permitindo a adaptação da coroa ao dente. Os animais foram então eutanasiados 21 ou 28 dias após a instalação das coroas e amostras do tecido gengival foram coletadas para posterior análise através do método de ELISA. O grupo de animais em que não foi realizada a instalação das coroas foi denominado "controle". Os resultados demonstraram que nas duas espessuras houve um aumento significativo na liberação das citocinas TNF- $\alpha$ e IL-1 $\beta$, podendo ser detectadas a partir de 21 e 28 dias, respectivamente $(\mathrm{P}<0,05$ : ANOVA, Teste de Tukey). Os resultados deste estudo sugerem que o trauma oclusal induz processo inflamatório no tecido periodontal local seguindo a clássica hierarquia da liberação de citocinas e causando, consequentemente, a sintomatologia dolorosa envolvida nessas condições.

Palavras-chave: Interferência oclusal, doença periodontal, inflamação.

\section{Introdução}

O objetivo deste estudo foi avaliar a presença da resposta inflamatória local no periodonto de elemento dental reabilitado com coroas metálicas que simulam o trauma oclusal.

\section{Resultados e Discussão}

Ratos machos Wistar $( \pm 150 \mathrm{~g}, \mathrm{n}=4$ 4-6/grupo, CEA \#4001-1) foram anestesiados e posicionados em um dispositivo para possibilitar a abertura bucal para a cimentação de coroas metálicas fundidas de $0,4 \mathrm{~mm}$ ou $0,7 \mathrm{~mm}$ de espessura (Fig. 1 e 2).

Figura 1. Mobilização do animal anestesiado para instalação das coroas.

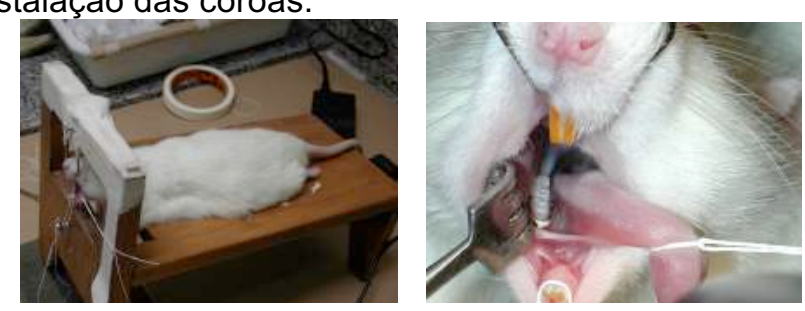

Figura 2. Instalação das coroas.

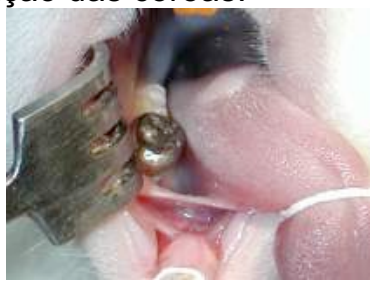

Os animais foram eutanasiados 21 ou 28 dias após a instalação das coroas e amostras do tecido gengival foram coletadas para posterior quantificação de

mediadores como TNF- $\alpha$ e IL-1 $\beta$ (ELISA). O grupo de animais em que não foi realizada a instalação das coroas foi denominado "controle".

Resultados: nas duas espessuras houve um aumento significativo na liberação das citocinas TNF- $\alpha$ e IL-1 $\beta$, podendo ser detectadas a partir de 21 e 28 dias, respectivamente $(\mathrm{P}<0,05:$ ANOVA, Teste de Tukey).

Figura 3. Quantificação de citocinas inflamatórias liberadas no tecido gengival no local da interferência oclusal.

A

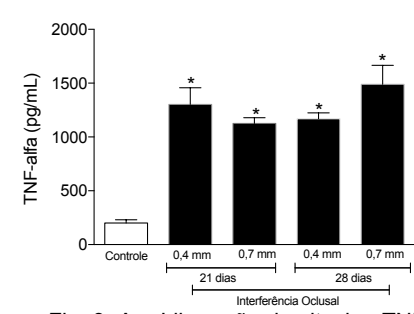

Fig. 3. A. - Liberação da citocina TNF-alfa ocorreu de forma significativamente maior nos grupos de animais com coroas de 0,4 ou 0,7 mm avaliados após 21 ou 28 dias da instalação das coroas quando comparado ao grupo controle. B - Liberação da citocina IL-1beta ocorreu de forma significativamente maior no grupo avaliado 28 dias após a instalação das coroas de 0,4 e 0,7 mm quando comparado ao grupo controle e aos grupos avaliados 21 dias após a instalação. O símbolo “*” indica uma resposta significativamente maior que os demais grupos ( $P<0,05$, ANOVA, Teste de Tukey).

\section{Conclusões}

O trauma oclusal induz processo inflamatório no tecido periodontal local seguindo a clássica hierarquia da liberação de citocinas e causando, consequentemente, a sintomatologia dolorosa envolvida nessas condições.

\section{Agradecimentos}

Ao CNPq, (PIBIC), pela bolsa de IC concedida. 